Çukurova Üniversitesi Mühendislik Mimarlık Fakültesi Dergisi, 33(2), ss. 189-198, Haziran 2018

Çukurova University Journal of the Faculty of Engineering and Architecture, 33(2), pp. 189-198, June 2018

\title{
Tornalamada Oluşan Yüzey Pürüzlülüğünün Yorulma Ömrüne Etkisinin Teorik Değerlendirilmesi
}

\author{
Hacı Bekir ÖZERKAN*1 \\ ${ }^{1}$ Gazi Üniversitesi, Teknik Bilimler MYO, Makine ve Metal Teknolojileri Bölümü, Ankara
}

$\ddot{\mathbf{O} z}$

Geliş tarihi: $19.02 .2018 \quad$ Kabul tarihi: 29.06 .2018

İmalat esnasında imalatın tipine göre oluşan yüzey pürüzlülük profili ve boyutları, yüzeylerde gerilme yığılması ve bunun sonucunda çatlak oluşumu ile başlayan yorulma hasar mekanizmasının oluşumunu tetikleyen bir yapı sergilemektedir. Bu çalışmada, alüminyum 6061-T913 alaşımından çap $40 \mathrm{~mm}$, boy $200 \mathrm{~mm}$ olarak hazırlanan deney numuneleri değişik kesme parametreleri ile CNC torna tezgahında işlendikten sonra oluşan yüzey pürüzlülükleri ölçülerek bu değerler yüzey pürüzlülüğüne bağlı olarak yorulma ömürlerinin teorik olarak hesaplanmasında kullanılmıştır. Daha sonra ölçülen yüzey pürüzlülükleri kullanılarak " $\sqrt{\text { area" }}$ " modeli ile yorulma ömrü hesaplanmış ve değerlendirilmiştir. Kesme hızının 100 m/dk'dan 400 m/dk’ya artırıldığında yüzey pürüzlülüğünün azaldığı, ilerlemenin artırılması ile yüzey pürüzlülüğünün arttığı tespit edilmiştir. Yapılan teorik hesaplamalar sonucunda ise yüzey pürüzlüğ̈̈nün artmasıyla yorulmanın daha düşük gerilmelerde, azalmasıyla ise yorulma hasarının daha yüksek gerilme değerlerinde başlayıp meydana gelebileceği anlaşılmıştır.

Anahtar Kelimeler: A16061-T913, Tornalama, Yüzey pürüzlülüğü, $\sqrt{\text { area }}$ yorulma ömrü modeli

\section{Theoretical Evaluation of the Surface Roughness Effect on the Fatigue Life in Turning}

\begin{abstract}
Surface roughness profile and values which occurs according to the type of machining, show a structure that triggers the fatigue damage mechanism which starts with formation of cracks on the surfaces. In this study, aluminum 6061-T913 alloy was processed by turning with different cutting parameters, then surface roughnesses were measured and these values were used to theoretical calculation of fatigue life depending on surface roughness. Test specimens prepared from Al6061 alloy $40 \mathrm{~mm}$ in diameter and $200 \mathrm{~mm}$ in length for turning with different cutting parameters. Then, roughness of the machined surfaces was measured and fatigue life was calculated and evaluated with the " $\sqrt{\text { area }}$ " model. When the cutting speed is increased the surface roughness is reduced and also increased by increment of feed rate. Theoretical calculations showed fatigue damage can be started and occured at higher stress values by decreasing surface roughness.
\end{abstract}

Keywords: Al 6061-T913, Turning, Surface roughness, $\sqrt{\text { area }}$ fatigue life model

"Sorumlu yazar (Corresponding author): Hacı Bekir ÖZERKAN, ozerkan@gazi.edu.tr 


\section{GíRiș}

Değişik imalat teknikleriyle şekillendirilmiş makine elemanlarının yorulma ömrü üzerinde en etkili faktörlerden biri yüzey koşullarıdır. Yorulma çatlaklarının genellikle serbest yüzeylerden başladığı uzun zamandır bilinen bir gerçektir. Mukavemet biliminde elemanların en üst yüzeyleri doğrudan dış yüklere maruz kalır ve bu yükler tarafından en fazla zorlanan, gerilmelerin en çok oluştuğu bölgeler olarak bilinmektedir [1]. Ayrıca, işletme ortamlarında ki açık çevresel koşullarda bu bölgeleri etkilemektedir. Dolayısıyla yüzey pürüzlülük yapısından ve diğer çentik etkisi meydana getirebilecek kusurlardan oluşan gerilme yı̆̆ılması ve oksitlenme gibi faktörler yorulmanın başlangıcı kabul edilen kılcal çatlakların oluşumuna katkıda bulunmaktadır. Çoğu durumda çatlağın oluşması ve büyümesi tercih edilen imalat yöntemi tarafindan üretilen yüzey bütünlüğüne atfedilir [2-4]. Yani makine elemanın kullanımı esnasında etkiyen dış yükler, yüzeylerde ki her bir pürüzlülük dalgası yorulma hasarını tetikleyebilecek en etkili çentik faktörlerinden birisidir. Şekil 1'de şematik olarak görüldüğü gibi ilk çatlak oluşumlarının bu dalgaları oluşturan vadi dip bölgelerinde başladığı varsayılmaktadır.

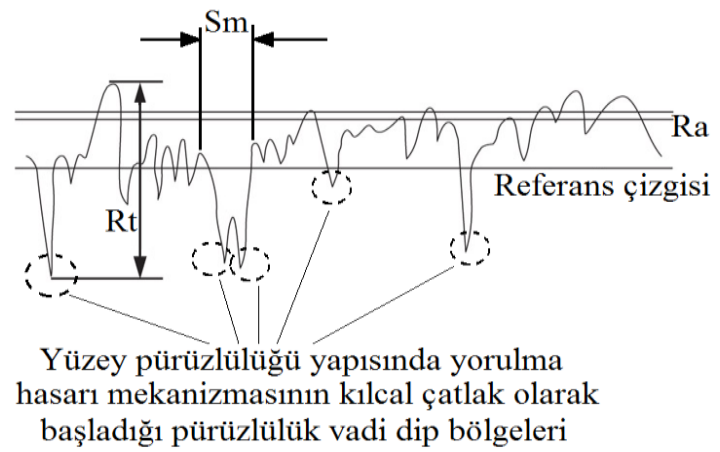

Şekil 1. Yüzey pürüzlülüğü profilinde tahmini çatlak başlangıcı bölgeleri

Makine elemanı şekillendirildikten sonra, imalatın türüne göre oluşan yüzey pürüzlülüğünün yorulmayı nasıl etkileyeceğini belirlemek için teorik hesaplamalar yorulma ömrünün kestirimi için oldukça faydalıdır. $\mathrm{Bu}$ çalışmada yüzey pürüzlülüklerini etkilediği bilinen farklı kesme hızı ve ilerleme değerlerinde tornalama işlemi gerçekleştirilmiştir. Farklı işleme parametreleri elde edilen yüzey pürüzlülükleri ölçülmüş ve teorik yorulma ömrü hesaplamaları $\sqrt{\text { area }}$ modeli kullanılarak yapılmıştır. Hesaplamalarda ölçüm uzunluğu boyunca olan pürüzlülük dalgasının en yüksek tepe-vadi uzunluğu "Rz" ve iki tepe noktası arasında ki en geniş mesafe "Sm" değerleri kullanılmıştır.

\section{LITERATÜR ARAŞTIRMASI}

$\mathrm{Bu}$ araştırma ile ilgili literatürde deneysel ve teorik çalışmalar mevcuttur. Field ve Kahles [5], yüzey bütünlüğünü, yüzeyin geometrik değerleri ile sertlik, kalıntı gerilmeler ve yüzey tabakalarının mikro yapıları gibi fiziksel özellikler arasında ki ilişki olarak tanımlamaktadır. Yani araştırmacılar yüksek statik ve dinamik zorlanmaların, makine elemanlarının imalatında elde edilen yüzey tamlığının, işlenmiş yüzeylerin ve hemen altında ki yüzey tabakalarının kalitesini ve makine bileşenlerinin yorulma ömrünü önemli derecede etkilediğini vurgulamışlardır. Yorulma üzerine gerçekleştirilen diğer çalışmalarda da mikro yap1, sertlik, yüzey pürüzlülüğü ve kalıntı gerilmeler gibi yüzey tamlığını etkileyen faktörlerin arasında, yüzey pürüzlülüğünün anahtar bir rol oynadığı bilinmektedir [3,6]. Malzemelerin geleneksel imalat teknikleriyle şekillendirilmesinde kullanılan kesme parametreleri de yüzey hassasiyeti ve bütünlüğü üzerine etki etmektedir [7]. Yüzey pürüzlülüğü ilerleme miktarı, kesme hızı ve derinliği gibi parametrelere bağlı olduğu birçok araştırmacı tarafindan vurgulanmaktadır $[8,9]$. Birçok araştırmacı tornalama işleminde ilerleme miktarı ve talaş derinliği değerlerinin yüzey pürüzlülüğüne artırıcı yönde olumsuz etki yaptığını ve ancak ideal bir kesme hızında en düşük pürüzlülük değerinin elde edilebileceğini ifade etmişlerdir [10-15]. Yüzey pürüzlülüğü faktörünün yorulma ömrü üzerine etkilerini tespit etmek amacıyla hesaplamalı ve deneysel birçok çalışma yapılmıştır. Tornalama ve taşlama ile elde edilen yüzey pürüzlülüğünün yorulma ömrü üzerine etkisinin araştırıldığı bir çalışmada, taşlamada ki boyut etkisinden dolayı yüzeylerde artan sertliğe rağmen ve sert tornalama ile elde edilen yüzey yapısının aynı yüzey pürüzlülüğü 
değerlerinde taşlamaya göre $\% 100$ daha uzun yorulma ömür değerlerini tespit etmişlerdir [16]. Eğilmeli yorulma deneylerinin gerçekleştirildiği bir çalışmada talaşlı imalat sonrasında oluşan bası kalıntı gerilmelerinin yorulma ömrüne artırıcı, artan yüzey pürüzlülüğünün ise azaltıcı yönde etkilerinin olduğu ifade edilmiştir $[3,17,18]$. Uygun işleme parametrelerinin seçilmesi, yüzey bitirme işlemlerinin dikkatlice yapılması, kalıntı gerilemelerin, yüzey pürüzlülüğünün azaltılması ve yüzey sertliğinin artırılması ile yorulma ömrünün uzatılabileceği belirtilmiştir [19]. Uygun işleme koşullarının ise küçük uç yarıçapına sahip ve kesici kenarı pah kırılmış takımlar ile düşük ilerleme hızları olduğu ifade edilmiştir. Murakami yaptığ 1 deneylerle ve soyut hesaplamalı yorulma çalışmaları sonucunda türettiği " $\sqrt{\text { area }}$ " modeli ile malzemenin içyapı kusurları ve yüzeysel süreksizlikleri boyutsal olarak teorik yorulma hesaplamalarında kullanmıştır. Sayısal hesaplamaları ile elde ettiği sonuçlar, deneysel çalışmaları ile oldukça yaklaşık olarak örtüşmektedir [20].

İmalat sanayinde çok yaygın olarak kullanılan Al6061 alaşımı, özellikleri itibariyle işlenebilirliği düşük bir malzemedir. $\mathrm{Bu}$ alaşım özellikle uçak bağlantı elemanları, kamera lens bağlantıları, kavramalar, deniz bağlantı parçaları ve donanımları, elektrik bağlantı parçaları ve konektörler, manyeto parçaları, fren pistonları, hidrolik pistonlar, cihaz parçaları, vana ve vana parçaları gibi birçok alanda kullanımı sürekli daha geniş bir alana yayılan bir malzemedir. Al alaşımları sahip olduğu yüksek çekme mukavemeti, korozyon direnci ve 1sıl iletkenlik gibi üstün özelliklerinin yanı sıra, sünek bir malzeme olması ve yapısında bulunan alaşım elementlerinin varlığı işlemeyi zorlaştıran başlıca etkenlerdir. Talaşlı işleme esnasında takıma sıvanma sorunu olduğu bilinen bir gerçektir [21]. Genellikle imalat resimlerinde istenilen yüzey kalitesi, farklı özelliklere sahip metallerin şekillendirilmesinde, ideal işleme değerlerinin seçimini zorlaştırmaktadır. Ayrıca değişik imalat tipleri de farklı geometride yüzey yapısı sunmaktadır. Dolayısıyla, bu değişik yüzey pürüzlülük desenleri ve büyüklükleri, makine elemanlarının yorulma ömrü üzerinde oldukça etkili olmaktadır. Yüzey pürüzlülük tepe ve çukur geometrileri, diş yüklerin etkimesiyle gerilme yığılmalarının olduğu bölgelerdir. Çatlak oluşumu bu yüzeylerden başlayarak ilerler ve kırılma veya kopma hasarı bu mekanizma ile gerçekleşir [20].

\section{MATERYAL VE METOT}

\subsection{Yorulma Ömrü Tahmininde $\sqrt{\text { area }}$ Modeli}

Metallerin yorulma ömrünün imalat sonrası değerlendirilmesinde yorulmaya etki eden en önemli parametrelerin; gerilme artırıcı olarak yüzey pürüzlülüğü, yüzey sertliği, işleme sonrası yüzeylerde oluşan artık gerilmeler, plastik deformasyon türüne bağlı olarak çalışma sertleşmesi veya yumuşaması ve yüzeylerde ki mikro yapının değişimi olarak ifade edilir [20]. Pratikte makine elemanlarına bu dört etki birlikte yorar ve hasara uğratır. Ancak hepsinin bir bütün olarak değerlendirilip sayısal olarak eşzamanlı kestirimi zordur. Dolayısıyla ayr1 ayrı değerlendirilmesi gerekmektedir. Murakami, konu üzerine yaptığı ilk çalışmalarında Maraging çeliğini çekme basma yorulma testine tabi tutarak yüzey pürüzlülüğünün etkisini araştırmıștır [22]. Geliştirdiği ve kabul gören modelinde yüzey pürüzlülük dalgalı yapısını sı ğ bir aralık ve derin bir çentik olarak tanımlamış ve bu tepe ve çukur alanını $\sqrt{\text { area }}$ olarak isimlendirmiştir.

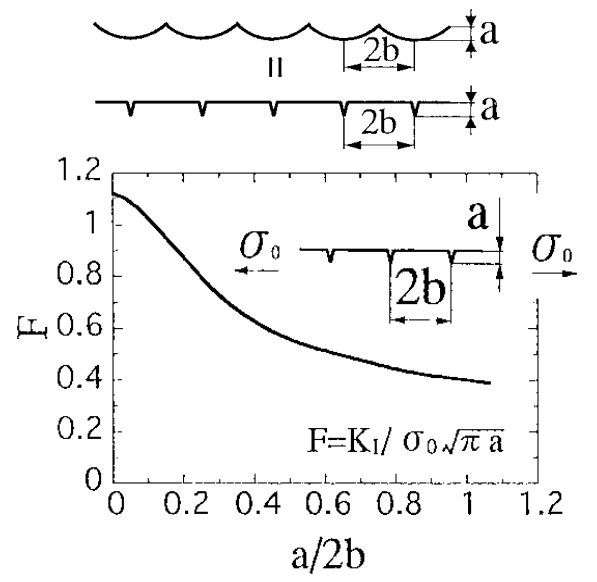

Şekil 2. Periyodik yüzey pürüzlülüğü çentikleri için gerilme şiddeti faktörü değişimi [20] 
Şekil 2'de işlenmiş yüzey üzerindeki periyodik pürüzlülük aralıkları için gerilme yoğunluğu faktörü " $K_{\mathrm{t}}$ " görülmektedir. " $F$ " terimi, yüzeyde çatlakların derinliğine ve aralığına bağlı olan geometrik bir düzeltme faktörüdür ve gerilme konsantrasyon faktörü $\left(\mathrm{K}_{\mathrm{t}}\right)$ Eşitlik 1'de vickers sertliğinin (HV) bir fonksiyonu olarak tanımlanmaktadır:

$K_{t}=\Delta K t h=(3,3) \cdot 10^{-3}(H V+120) \cdot(\sqrt{\text { area }})^{1 / 3}$

Murakami yüzey pürüzlülüğünü yorulmaya göre modellerken Şekil 1'de pürüzlülük dalgasının genişliğini ve derinliğini sırasıyla $2 b$ ve a ifadeleri ile tanımlamıştır. Bu çalışmada standart pürüzlülük ölçümlerinde bu tanımlamaları ifade eden $\mathrm{Rz}$ ve Sm parametreleri teorik hesaplamalarda kullanılmıştır. (Eşitlik 2) Rz ölçüm aralığında ölçülen maksimum tepe ve çukurcuk değerlerinin (Rt) ortalaması olup Şekil 3'te şematik olarak belirtilmiştir.

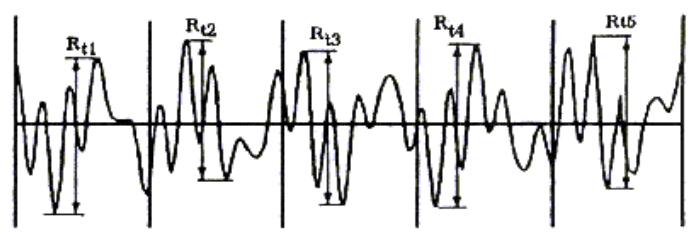

Şekil 3. Ölçüm aralığında referans çizgisine göre maksimum tepe çukurcuk değeri

$\mathrm{Rz}(\mathrm{DIN})=\frac{\mathrm{R}_{\mathrm{t} 1}+\mathrm{R}_{\mathrm{t} 2} \ldots \ldots \ldots \ldots \ldots+\mathrm{R}_{\mathrm{tn}}}{\mathrm{n}}=\frac{1}{\mathrm{n}} \sum_{\mathrm{i}=1}^{\mathrm{n}} \mathrm{R}_{\mathrm{ti}}$

"Sm" ise ölçüm uzunluğunda pürüzlülük dalga tepe noktaları arasında ki mesafe olarak tanımlanmaktadır (Şekil 4) ve yorulma modelindeki " $2 \mathrm{~b}$ " terimini ifade etmektedir. Yorulma hesaplamalarında pürüzlülük ölçümlerinde standartlaşmış bu iki ölçüm değeri kullanılmıştır.

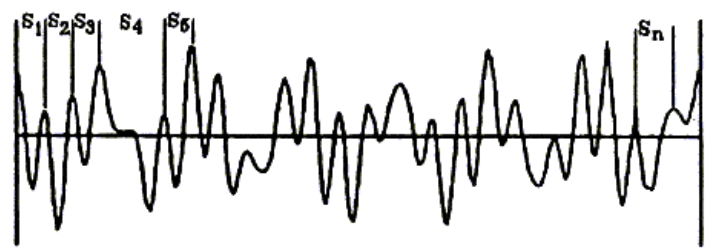

Şekil 4. Pürüzlülük tepe noktaları arası mesafe
Murakami'nin önerdiği kestirim modelinde $\mathrm{R}=-1$ (gerilme oranı) olarak tanımlanmıştır. Yani tam değişken dinamik yorulma durumunu göz önünde bulundurulmuştur. Burada " $\sqrt{\text { area }}$ " ifadesi yüzeydeki profil dalgalarını ifade eden hata boyutudur. Eşitlik 3 ve 4 genel yorulma ömür formülünde pürüzlülük tepe ve çukur değerlerinin hangi aralıkta olduğun açıklanmaktadır.

$\mathrm{a} / 2 \mathrm{~b}<0,195$ koşulu için;

$(\operatorname{area})^{1 / 2} / 2 b \cong 2,97(a / 2 b)-3,51(a / 2 b)^{2}-9,74(a / 2 b)^{3}$

$\mathrm{a} / 2 \mathrm{~b}>0,195$ koşulu için;

(area) $1 / 2 / 2 b \cong 0,38$

Eşitlik 5'te $\sqrt{\text { area }}$ değerlerini yerine koyarak yüzey pürüzlülük aralık ve çukurcukları için yorulma ömrü kestirimi yapılabilmektedir. Burada " $\sigma w "$ müsaade edilen teorik yorulma ömrünü " $\alpha$ " ise gerilme hassasiyet faktörüdür ve aşağıdaki Eşitlik 6'daki gibi ifade edilmiştir:

${ }_{\mathrm{w}}=\frac{1.43\left(\mathrm{H}_{\mathrm{V}}+120\right)}{(\sqrt{\text { area }})^{1 / 6}}\left[\frac{1-\mathrm{R}}{2}\right]^{\alpha}$

$\alpha=0,226+\mathrm{HV} \times 10^{-4}$

Gerilme oranı " $R$ " ise Eşitlik 7'deki genel formülle tanımlanmış ve eşitlikte bulunan $\sigma_{m}$ ortalama gerilmeyi ifade etmektedir.

$\mathrm{R}=\frac{\sigma_{\mathrm{m}}-\sigma_{\mathrm{w}}}{\sigma_{\mathrm{m}}+\sigma_{\mathrm{w}}}$

$\sqrt{\text { area }}$ modeli ile Murakami'nin geliştirdiği bir diğer parametre ise yüzeydeki pürüzlülük süreksizliklerinde oluşacak gerilme yı ğılmalarını ifade eden gerilme şiddeti faktörüdür. Bu faktörün bilinmesi durumunda çentik bölgesinde ki tüm gerilme ve genlemelerin büyüklüğü tespit edilebilir. $\mathrm{Bu}$ gerilme değerleri ise belirli bir eşik değere ulaştığında çatlak ilerler. Bu değer farklı geometriler ve yükleme durumları için literatürde mevcut olup bu çalışmadaki hesaplamalarda $\sqrt{\text { area }}$ ifadesinin bulunduğu Eşitlik 1 kullanılmıştır. 


\subsection{Malzeme ve Deneysel Yöntem}

$\mathrm{Bu}$ çalışmada, deney numunelerinin hazırlanması için alüminyum alaşımı olan Al 6061-T913 dairesel kesitli çubuk malzeme, piyasadan $40 \mathrm{~mm}$ çapında temin edilmiş olup kimyasal bileşimi ve mekanik özellikleri Çizelge 1'de verilmiştir.

Çizelge 1. Al6061 malzemenin kimyasal bileşimi (\% Ağırlık) ve mekanik özellikleri

\begin{tabular}{|c|c|c|c|}
\hline \multicolumn{2}{|c|}{$\begin{array}{c}\text { Kimyasal } \\
\text { bileşim }(\%)\end{array}$} & \multicolumn{2}{|c|}{ Mekanik özellikler } \\
\hline $\mathrm{Al}$ & $95,8-98,6$ & Brinell Sertliği & 123 \\
\hline $\mathrm{Cr}$ & $0,04-0,35$ & Vickers Sertliği & 139 \\
\hline $\mathrm{Cu}$ & $0,15-0,40$ & $\begin{array}{l}\text { Nihai Çekme } \\
\text { Dayanımı }\end{array}$ & $460 \mathrm{MPa}$ \\
\hline $\mathrm{Fe}$ & $<=0,70$ & Akma Muk. & $455 \mathrm{MPa}$ \\
\hline $\mathrm{Mg}$ & $0,80-1,2$ & Elastisite Modülü & $69.0 \mathrm{GPa}$ \\
\hline Mn & $<=0,15$ & Poisson Oranı & 0,33 \\
\hline $\mathrm{Si}$ & $0,40-0,80$ & Kayma Modülü & $26,0 \mathrm{GPa}$ \\
\hline $\mathrm{Ti}$ & $<=0,15$ & $\begin{array}{l}\text { Kayma } \\
\text { Mukavemeti }\end{array}$ & $240 \mathrm{MPa}$ \\
\hline $\mathrm{Zn}$ & $<=0,25$ & & \\
\hline
\end{tabular}

Çalışmada, bir silindirik deney numunesi üzerinde, Şekil 5'te gösterildiği gibi Çizelge 2'de belirtilen üç farklı kesme işlemi uygulanmıştır. Böylelikle yüzey pürüzlülüklerinin ölçülmesi için; bir deney numunesinden altı işlenmiş kısım elde edilmiştir.

Tornalamada yüzey pürüzlülüğüne diğer işleme parametrelerine göre en fazla etki eden değişkenin ilerleme miktarı olduğu yapılan çalışmalardan bilinmektedir [13, 21-23]. Dolayısıyla tercih edilen takım ile değişik ve geniş aralıkta pürüzlülük değerleri elde etmek amacıyla ilerleme miktarı Çizelge 2'de belirtildiği gibi üç farklı değer olarak seçilmiştir.

Deney numunelerinin işlenmesinde takım üreticisi Sandvik firmasının önerdiği VCGX 1102 04-AL H10 formunda kesici uç ve buna uygun SVHCL 2525M 22-R2 takım tutucu kullanılmıştır.

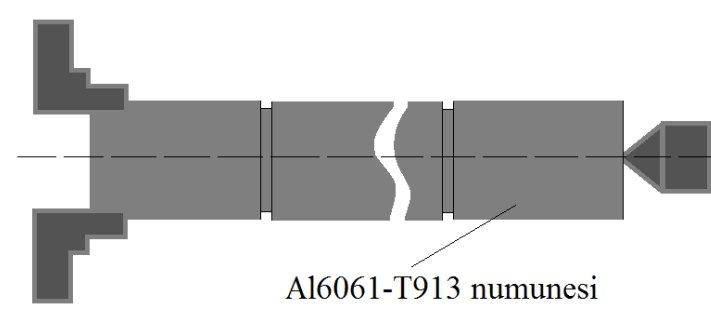

Şekil 5. İş parçası bağlantısının şematik gösterimi

Deneylerde kullanılan kesme parametreleri ISO 3685 standardına göre değerlendirilmiş ve işlemelerde değişik yüzey pürüzlülüğü değerleri elde etmek amaciyla ilerleme değerleri temel değişken olarak dikkate alınmıştır. Çizelge 2'deki değerlerle işlemeler yapılmıştır. Tercih edilen kesici takıma göre üretici firmanın tavsiye ettiği en uygun kesme hızları yerine geniş bir işleme hızı veri aralığında nasıl sonuçlar alınabileceğini görmek için 100, 200 ve $400 \mathrm{~m} /$ dak hızları tercih edilmiştir. Deneylerde her işleme için yeni takım kullanılarak yüzey pürüzlülüğüne kesici uçta meydana gelebilecek aşınmaların etkisi önlenmiştir.

Çizelge 2. İşleme deneylerinde kullanılan kesme parametreleri

\begin{tabular}{|c|c|c|c|c|c|c|}
\hline Deney No & $\mathbf{1}$ & $\mathbf{2}$ & $\mathbf{3}$ & $\mathbf{4}$ & $\mathbf{5}$ & $\mathbf{6}$ \\
\hline $\mathrm{V}(\mathrm{m} / \mathrm{dak})$ & 100 & 200 & 400 & 100 & 200 & 400 \\
\hline $\mathrm{f}(\mathrm{mm} / \mathrm{dev})$ & \multicolumn{3}{|c|}{0,2} & \multicolumn{3}{|c|}{0,4} \\
\hline $\mathrm{a}(\mathrm{mm})$ & \multicolumn{3}{|c|}{2} & \multicolumn{3}{|c|}{2} \\
\hline Deney No & $\mathbf{7}$ & $\mathbf{8}$ & $\mathbf{9}$ & $\mathbf{1 0}$ & $\mathbf{1 1}$ & $\mathbf{1 2}$ \\
\hline $\mathrm{V}(\mathrm{m} / \mathrm{dak})$ & 100 & 200 & 400 & 100 & 200 & 400 \\
\hline $\mathrm{f}(\mathrm{mm} / \mathrm{dev})$ & \multicolumn{3}{|c|}{0,6} & \multicolumn{3}{|c|}{0,8} \\
\hline $\mathrm{a}(\mathrm{mm})$ & \multicolumn{3}{|c|}{2} & \multicolumn{3}{|c|}{2} \\
\hline
\end{tabular}

Çizelge 2'deki parametrelere göre, $40 \mathrm{~mm}$ çapında ve $200 \mathrm{~mm}$ boyundaki deney malzemeleri CNC torna tezgahında işlenmiştir. Böylece CNC torna tezgâhında $\varnothing 40 \mathrm{~mm}$ ve $30 \mathrm{~mm}$ boyunda toplamda 12 adet işlenmiş parça elde edilmiştir. Numuneler ile deneysel işlemelere başlamadan önce piyasadan temin edilen işparçasının üzerindeki salgıyı ve mevcut yüzey pürüzlülüğünün olumsuz etkilerini elimine etmek için işparçaları üzerinden $1 \mathrm{~mm}$ derinliğinde talaş kaldırılmıştır. Yüzey 
pürüzlülüğü ölçümleri MAHR marka MarSURF M300 taşınabilir cihaz ile gerçekleştirilmiştir. Ölçümlerin doğruluğunu ve güvenilirliğini sağlamak açısından ölçümler 4 farklı noktadan alınarak teorik hesaplamalarda ortalaması alınarak kullanılmıştır.

\section{BULGULAR}

\subsection{Yüzey Pürüzlülüğünün Değerlendirilmesi}

Değişik parametrelerde işlenen deney numunelerinin dört farklı noktadan elde edilen ortalama yüzey pürüzlülük değerleri $(\mathrm{Ra})$, bu yüzeylere ait örnekleme uzunluklarının profildeki en yüksek 5 tepe ile en derin 5 vadinin genliklerinin aritmetik ortalaması (Rz) ve profildeki en yüksek pürüzlülük değerleri (Rmax) ölçülmüş ve ortalaması alınarak Çizelge 3 'de listelenmiştir.

Çizelge 3. Ölçülen yüzey pürüzlülük değerleri

\begin{tabular}{|c|c|c|c|c|c|c|}
\hline Deney No & $\mathbf{1}$ & $\mathbf{2}$ & $\mathbf{3}$ & $\mathbf{4}$ & $\mathbf{5}$ & $\mathbf{6}$ \\
\hline $\mathrm{V}(\mathrm{m} / \mathrm{dak})$ & 100 & 200 & 400 & 100 & 200 & 400 \\
\hline $\mathrm{f}(\mathrm{mm} / \mathrm{dev})$ & \multicolumn{3}{|c|}{0,2} & \multicolumn{3}{c|}{0,4} \\
\hline $\mathrm{a}(\mathrm{mm})$ & \multicolumn{3}{|c|}{2} & \multicolumn{3}{|c|}{2} \\
\hline $\mathrm{Rz}(\mu \mathrm{m})$ & 17,7 & 16,98 & 15,61 & 19,87 & 18,65 & 17,45 \\
\hline $\mathrm{Sm}(\mu \mathrm{m})$ & 547,2 & 387,5 & 331,9 & 816,7 & 490,3 & 445,8 \\
\hline $\mathrm{Ra}(\mu \mathrm{m})$ & 3,98 & 2,83 & 2,43 & 5,92 & 3,57 & 3,25 \\
\hline Deney No & $\mathbf{7}$ & $\mathbf{8}$ & $\mathbf{9}$ & $\mathbf{1 0}$ & $\mathbf{1 1}$ & $\mathbf{1 2}$ \\
\hline $\mathrm{V}(\mathrm{m} / \mathrm{dak})$ & 100 & 200 & 400 & 100 & 200 & 400 \\
\hline $\mathrm{f}(\mathrm{mm} / \mathrm{dev})$ & \multicolumn{5}{|c|}{0,6} & \multicolumn{5}{c|}{0,8} \\
\hline $\mathrm{a}(\mathrm{mm})$ & \multicolumn{7}{|c|}{2} & \multicolumn{5}{|c|}{2} \\
\hline $\mathrm{Rz}(\mu \mathrm{m})$ & 22,16 & 19,21 & 18,56 & 25,17 & 23,54 & 20,71 \\
\hline $\mathrm{Sm}(\mu \mathrm{m})$ & 1035 & 898,6 & 759,7 & 1181 & 1033 & 900 \\
\hline $\mathrm{Ra}(\mu \mathrm{m})$ & 7,49 & 6,51 & 5,51 & 8,54 & 7,48 & 6,52 \\
\hline
\end{tabular}

Çizelge 3'te görülen değerler, farklı kesme hızı, ilerleme ve aynı talaş derinliğine bağlı olarak yüzey pürüzlülüğü parametrelerindeki değişimi göstermek amacıyla bir bütün olarak gösterilmiştir. Talaşlı imalat uygulamalarında işlenebilirliğin önemli bir göstergesi yüzey pürüzlülüğüdür. Yüzey pürüzlülüğü, ağırlıklı olarak sırasıyla ilerleme miktarına, kesme hızına ve işleme derinliğine göre değişim göstermektedir. Daha önce gerçekleştirilen tornalama çalışmalarından bilindiğine göre kesme hızının artması ile yüzey pürüzlülüğü azaldığı ve ilerlemenin etkisinin kesme hızına göre daha fazla olduğu belirtilmiştir
[11-15, 24]. Al6061-T913 alaşımının tornalama işleminde kesme hızının artmasıyla yüzey pürüzlülüğünde azalma meydana geldiği ve ilerlemenin artışıyla pürüzlülüğün arttığı yapılan deneysel sonuçlardandır. Dolayısıyla yüzey pürüzlülüğü ile ilerleme arasında tedricen artan orantılı bir ilişki söz konusudur. Ölçülen $\mathrm{Sm}$ ve Rz değerleri incelendiğinde ilerleme değerinin artışıyla bu değerler belirgin artış göstermiştir.

\subsection{Yüzey Pürüzlülüğüne Bağlı Olarak Teorik Yorulma Ömrü Değişimi}

İşlemeler sonrasında yapılan yüzey pürüzlülük ölçüm parametrelerinden $\mathrm{Rz}$ ve $\mathrm{Sm}$ değerleri ve $\sqrt{\text { area }}$ modeli kullanılarak değişik tornalama parametreleriyle işlenmiş yüzeylerin teorik yorulma limit gerilme değerleri ve eşik gerilme şiddeti faktörü değerleri hesaplanmış ve Çizelge 4'te verilmiştir. Yüzey pürüzlülüğü parametrelerinden $\mathrm{Rz}$ pürüzlülük dalgasının en yüksek tepe-vadi arasındaki boyut olup, hesaplamalarda bu değer Murakami'nin modelindeki pürüzlülüğün çukur yüksekliği olarak kabul edilmiştir. Sm ise pürüzlülük tepe noktaları arasında ki mesafe yani bir pürüzlülük vadisinin genişliği olarak kullanılmıştır. Yüzey pürüzlülük ölçüm parametrelerinden bu ikisi, $\sqrt{\text { area }}$ modelinde çatlak oluşumu için işlenmiş yüzeylerdeki pürüzlülük dalgalarındaki iki tepe arasında bulunan en yüksek düzlemsel alanın hesaplanmasında ortalama değer olarak tercih edilmiştir. Çizelge 4'te görüldüğü üzere $\mathrm{Rz}$ ve $\mathrm{Sm}$ değerleri kullanılarak hesaplanmış $\sqrt{\text { area }}$ değerleri incelendiğinde kesme hızı arttıkça yorulmayı etkileyen bu değer azalmakta ve ilerleme arttıkça ise bu değer artış göstermektedir. İşlenmiş yüzeylerde oluşan değişik pürüzlülük değerleri ve geometrileri yorulma hasar mekanizmasını başlatan en önemli parametrelerdendir [20]. Elemana etkiyen dış yükler elemanı çeki yönünde zorlarsa çatlak başlangıcının Şekil 2'de belirtilen bu bölgelerden başlamasının kaçınılmaz ve buraların en fazla gerilme yığılma bölgeleri olduğu bilinen bir gerçektir [7,20]. " $\sqrt{\text { area }}$ " değerinin azalması yorulma limit ömrünü artırmakta ve artmasıyla ise tersi durumun söz konusu olduğu Çizelge 4'te açıkça görülmektedir. 
Çizelge 4. $\sqrt{\text { area }}$ modeli ile hesaplanmış yorulma ömür ve $\Delta \mathrm{K}$ th değerleri

\begin{tabular}{|c|c|c|c|}
\hline $\begin{array}{c}\text { Deney } \\
\text { No }\end{array}$ & $\begin{array}{c}\sqrt{\text { area }} \\
(\mu \mathrm{m})\end{array}$ & $\begin{array}{c}\text { Teorik } \\
\text { Yorulma } \\
\text { Gerilme } \\
\text { Değeri (MPa) }\end{array}$ & $\begin{array}{c}\text { Essik } \\
\text { Gerilme } \\
\text { Şiddeti } \\
\text { Faktörü }\end{array}$ \\
\hline 1 & 50,37913 & 193 & 3,2 \\
\hline 2 & 47,48838 & 195 & 3,1 \\
\hline 3 & 43,45659 & 198 & 3,0 \\
\hline 4 & 57,20243 & 189 & 3,3 \\
\hline 5 & 52,63751 & 191 & 3,2 \\
\hline 6 & 49,16881 & 194 & 3,1 \\
\hline 7 & 64,0504 & 185 & 3,4 \\
\hline 8 & 55,5352 & 190 & 3,3 \\
\hline 9 & 53,4238 & 191 & 3,2 \\
\hline 10 & 72,7711 & 181 & 3,6 \\
\hline 11 & 67,91255 & 183 & 3,5 \\
\hline 12 & 59,72916 & 187 & 3,3 \\
\hline
\end{tabular}

Ayrıca işlemeler sonrasında ölçülen pürüzlülük değerleri kullanılarak hesaplanan diğer önemli değer ise eşik gerilme şiddeti faktörüdür. Bu değer yüzeydeki pürüzlülüğe bağlı olarak en yüksek tepe-vadi dalgasında çatlağın başlayabileceği yerdeki yükleme ve geometriye bağlı gerilme yığılmasını, diğer bir ifadeyle sınır kırılma tokluğunu ifade etmektedir. Yani bu eşik gerilme şiddeti değeri aşıldığında çatlak oluşumu başlayıp ilerleme şeklinde hasar kendini göstermektedir. Yapılan hesaplamalar sonucunda eşik gerilme şiddeti değerleri Çizelge 4'te belirtilmiştir. Buna göre kesme hızı arttıkça bu faktör azalmış, ilerleme hızı ile ise artış göstermiştir. En yüksek eşik gerilme şiddeti faktörü $\mathrm{f}=0,8 \mathrm{~mm} / \mathrm{dev}$ ilerlemede $\mathrm{V}=100 \mathrm{~m} /$ dak kesme hızında 3,6 MPa.m ${ }^{1 / 3}$ olarak, en düşük değer ise $\mathrm{f}=0,2 \mathrm{~mm} / \mathrm{dev}$ ilerlemede $\mathrm{V}=400 \mathrm{~m} /$ dak kesme hızında $3 \mathrm{MPa}^{\mathrm{m}} \mathrm{m}^{1 / 3}$ olarak hesaplanmıştır.

Şekil 6'da kesme hızı ile teorik yorulma ömrü değişimi görülmektedir. Grafik incelendiğinde kesme hızı arttıkça tüm işlemelerde yüzey pürüzlülüğüne bağlı olarak değerlendirilen teorik yorulma ömrü artış göstermiştir. Bu durum kesme hızına bağlı olarak yüzey pürüzlülüğünün azalmasından kaynaklanmıştır. Düşük yüzey pürüzlülüğü yorulma hasar mekanizmasını başlatma olasılığını azaltmıştır. Bu durum makine elemanlarında, yorulmanın daha yüksek gerilme değerlerinde başlayacağı anlamına gelmektedir. Kısacası, kesme hızı artışının yorulmayı azaltıcı yönde etki yaptığı söylenebilir. En yüksek yorulma ömrü değeri $\mathrm{f}=0,2 \mathrm{~mm} / \mathrm{dev}$ ilerlemede $\mathrm{V}=400 \mathrm{~m} /$ dak kesme hızında $198 \mathrm{MPa}$ olarak, en düşük yorulma ömrü ise $\mathrm{f}=0,8 \mathrm{~mm} / \mathrm{dev}$ ilerlemede $\mathrm{V}=100 \mathrm{~m} /$ dak kesme hızında $181 \mathrm{MPa}$ olarak hesaplanmıştır. Şekil 6'da, yorulma ömrü değerleri artan bir yapıda olup, çalışmada kullanılan kesme hızı değerlerinden daha yüksek kesme hızlarında ki işlemelerin yapılması halinde yorulma ömrünün belirli bir değere kadar da artacağ1 söylenebilir.

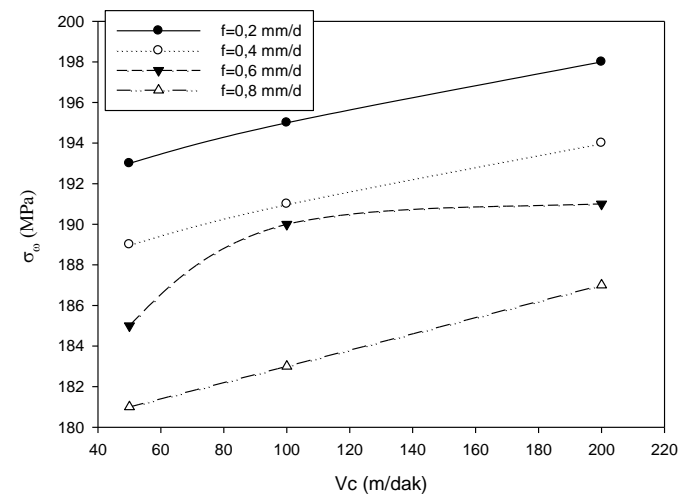

Şekil 6. Kesme hızı ile teorik yorulma ömrü değişimi

Hesaplanmış teorik yorulma limit gerilme değeri ile ilerleme hızının değişimi ise Şekil 7'de görüldüğü gibidir. Grafiklerde ilerleme hızının yorulma ömrünü artıran bir etkisinin olduğu açık bir gerçektir. Bunun sebebi ilerlemenin işlenmiş yüzeylerdeki pürüzlülük değerlerini artırıcı yönde etkisinin olmasıdır. Pürüzlülük tepe-vadi değerlerindeki artış makine elemanlarının yüzeylerinde, daha düşük gerilme değerlerinde çatlak oluşturacağı anlamına gelmektedir. Böylelikle Al6061-T913 alaşımının torna ile şekillendirilmesinde ilerleme artışı etkisinin imalat sonrasında işletme ömrü açısından olumsuz etki yaptığı hesaplamalardan kestirilebilir. Bu alaşımın 
bu imalat tekniği ile şekillendirilmesinde düşük ilerleme hızlarının ideal olabileceği söylenebilir.

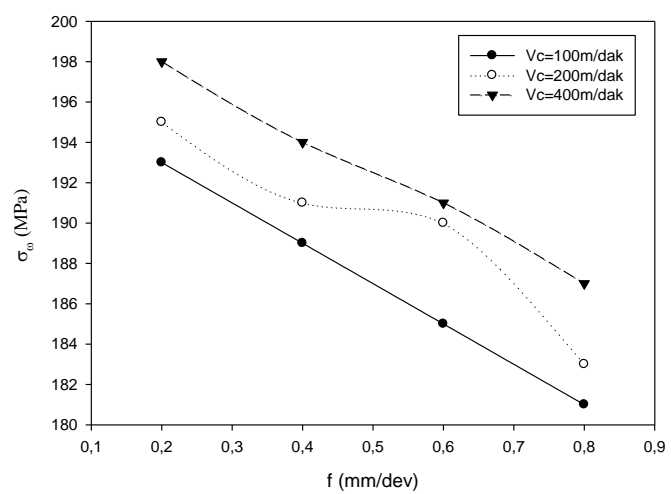

Şekil 7. İlerleme hızı ile teorik yorulma ömrünün değişimi

\section{SONUÇLAR}

Al6061-T913 alaşımından silindirik numunelerin farklı kesme parametreleriyle tornalanması işlemiyle üretilen yüzeylerden ölçülen yüzey pürüzlülük parametrelerinde $\mathrm{Rz}$ ve $\mathrm{Sm}$ değerleri kullanılarak $\sqrt{\text { area }}$ modeli ile teorik yorulma limit gerilme değerleri ve eşik gerilme şiddeti faktörü değerleri hesaplanmıştır. Yapılan ölçümlerin ve hesaplamaların sonucunda Al6061-T913 alaşımının tornalamasında üretilen yüzey pürüzlülükleri ile ilgili aşağıda belirtilen sonuçlara varılmıştır.

En düşük yüzey pürüzlülüğü değerleri kesme hızının $400 \mathrm{~m} /$ dak., ilerlemenin $0,2 \mathrm{~mm} / \mathrm{dev}$ olduğu işlemelerde ölçülmüştür. Yani işlemeler pürüzlülük açısından değerlendirilirse, bu işleme şartlarında en yüksek yüzey kalitesi elde edilmiştir. Aynı ilerleme hızı değerlerinde yapılan işlemelerde kesme hızı arttıkça yüzey pürüzlüğü azalmıştır.

En yüksek yüzey pürüzlülüğü değerleri ise; kesme hızının $100 \mathrm{~m} /$ dak., ilerlemenin $0,8 \mathrm{~mm} / \mathrm{dev}$. olduğu durumda ortaya çıkmıştır.

İlerleme ile yüzey pürüzlülüğü arasında doğrusal bir bağlılaşım vardır. İlerlemenin artmasıyla yüzey pürüzlülüğü de artmaktadır. İlerlemenin yüzey pürüzlülüğüne etkisinin kesme hızından daha etkili olduğu tespit edilmiştir.

Rz ve Sm yüzey pürüzlülük değerleri kullanılarak yapilan $\sqrt{\text { area }}$ modeli yorulma ömür hesaplamalarına göre ilerleme hızı arttıkça yüzey pürüzlülük profilindeki en derin tepe-vadi değerleri de artmıştır. Buna göre ilerleme artışı ile oluşan pürüzlük artışı yorulmayı olumsuz etkilemiş, en düşük yorulma ömrü en yüksek pürüzlülük değerlerinde tespit edilmiştir. İlerleme değerinin artışı yorulma ömrünü azaltmaktadır.

Kesme hızının artışı ile gerilme yı̆̆ılmaların oluşacağı pürüzlülük profilindeki en büyük tepevadi değerleri de azalmış böylelikle yorulmayı tetikleyecek daha düşük süreksizlikler oluşmuştur. Böylelikle en yüksek teorik yorulma gerilme değerleri en yüksek kesme hızında ve en düşük ilerleme değerlerinde elde edilmiştir. En yüksek yorulma ömrü değeri $\mathrm{f}=0,2 \mathrm{~mm} / \mathrm{dev}$ ilerlemede $\mathrm{V}=400 \mathrm{~m} /$ dak kesme hızında $198 \mathrm{MPa}$ olarak, en düşük yorulma ömrü ise $\mathrm{f}=0,8 \mathrm{~mm} / \mathrm{dev}$ ilerlemede $\mathrm{V}=100 \mathrm{~m} /$ dak kesme hizında $181 \mathrm{MPa}$ olarak hesaplanmıştır. $\mathrm{Bu}$ durum belirgin şekilde yüzey pürüzlülüğünün malzemelerde çentik etkisi oluşturduğunun bir göstergesidir.

Çatlağın başlama ihtimalinin ve diş zorlanmalar etkisinde gerilme yığılmalarının en yüksek olduğu vadi dip bölgelerinde, çatlak oluşumunu başlatmasını ifade eden diğer önemli bir parametre olan eşik gerilme şiddeti faktörüdür. Pürüzlülük ölçümleri sonucunda elde edilen değerler kullanılarak hesaplanan $\Delta \mathrm{K}$ th değerleri ise kesme hızı artışı ile azalmış, ilerleme ile artmıştır. Çentik bölgesindeki gerilme yoğunluğu olarak ve çatlak ilerleme hızıyla doğru orantılı olarak değiştiği bilinen bu ifade azalan yüzey pürüzlülüğü değerleriyle azalma eğilimi göstermiştir. Yani kesme hızının bu değeri azaltması, pürüzlülük vadi dip bölgesinde gerilme yoğunluğunun azalması anlamına gelmektedir.

Uygun takım geometrisi, ilerleme ve kesme hızı ile işletme koşullarına uygun ve yorulma ömrü daha uzun yüzey pürüzlülüğü elde edilebilmektedir. Dolayısıyla makine elemanlarının imalat sonrasında elde edilen yüzey pürüzlülüğünü 
yorulma ömrüne etki edeceği göz önünde bulundurularak imalat tipi ve parametrelerini seçmek büyük önem taşımaktadır.

\section{KAYNAKLAR}

1. Schmid, R. S., Hamrock, B. J., H., Jacobson, B.O., 2013. Fundamentals of Machine Elements (Third Edition), CRC Press, 161.

2. Taylor, D., Clancy, O., 1991. The Fatigue Performance of Machined Surfaces. Fatigue \& Fracture of Engineering Materials \& Structures 14(2-3), 329-336.

3. Javidi, A., Rieger, U., Eichlseder, W., 2008. The Effect of Machining on the Surface Integrity and Fatigue Life. International Journal of Fatigue, 30(10), 2050-2055.

4. Pramanik, A., Dixit, A.R., Chattopadhyaya, S., Uddin, M.S., Dong, Y., Basak, A.K., Littlefair, G., 2017. Fatigue Life of Machined Components. Advances in Manufacturing, $5(1), 59$.

5. Field, M., Kahles, J., 1971. Review of Surface Integrity of Machined Components. Ann CIRP 20, 153-63.

6. Capello, E., 2005. Residual Stresses in Turning Part I: Influence of Process Parameters. Journal of Materials Processing Technology, 160(2), 221-228.

7. Griffiths, B.J., 2001. Manufacturing surface technology, in: Surface Integrity and Functional Performance, Penton Press. London, 21.

8. Thamizhmanii, S., Saparudin, S., Hasan, S., 2007. Analyses of Surface Roughness by Turning Process using Taguchi Method. Journal of Achievements in Materials and Manufacturing Engineering, 20(1-2), 503-506.

9. Qehaja, N., Jakupi, K., Bunjaku, A., Bruçi, M., Osmani, H., 2015. Effect of Machining Parameters and Machining Time on Surface Roughness in Dry Turning Process. Procedia Engineering, 100, 135-140.

10. Kishawy, H.A., Elbestawi, M.A., 1999. Effects of Process Parameters on Material Side Flow During Hard Turning. International Journal of Machine Tools and Manufacture, 39, 1017-1030.
11.Huang, L., Chen, C., 2001. A Multiple Regression Model to Predict In-process Surface Roughness in Turning. Journal of Industrial Technology, 17(2), 1-8.

12. Puertas, I., Luis Perez, C.J., 2003. Surface Rougness Prediction By Factorial Design of Experiments in Turning Processes. Journal of Materials Processing Technology, 143, 390-396.

13. Tekaslan Ö., Gerger, N., Şeker, U., 2008. AISI 304 Östenitik Paslanmaz Çeliklerde Kesme Parametrelerine Bağlı Olarak Yüzey Pürüzlülüklerinin Araştırılması, BAÜ FBE Dergisi, 10(2), 3-12.

14.Zawada-Tomkiewicz, A., 2011. Analysis Of Surface Roughness Parameters Achieved By Hard Turning with the use of PCBN Tools, Estonian Journal of Engineering, 17(1), 88-99.

15. Yamanea, Y., Ryutaroa, T., Tadanori, S., Ramirez I.M., Keiji, Y., 2017. A New Quantitative Evaluation for Characteristic of Surface Roughness in Turning, Precision Engineering, 50, 20-26.

16. Yu-kui, G., Xiang-bin, L., Qing-iang, Y., Mei, Y., 2007. Influence of Surface Integrity on Fatigue Strength of 40CrNi2Si2MoVA Steel. Materials Letters, 61(2), 466-469.

17. Davies, D.P., Jenkinsa, S.L., Legga, S.J., 2014. The Effect Machining Processes Can Have on the Fatigue Life and Surface Integrity of Critical Helicopter Components. Procedia CIRP 13, 25-30.

18. Torres, M., Voorwald, H., 2002. An Evaluation of Shot Peening, Residual Stress and Stress Relaxation on The Fatigue Life of AISI 4340 Steel. International Journal of Fatigue 24(8), 877-886.

19. Hashimoto, F., Guo, Y.B., Warren, A.W., 2006. Surface Integrity Difference between Hard Turned and Ground Surfaces and its Impact on Fatigue Life. CIRP Annals, 55(1), 81-84.

20. Murakami, Y., 2002. Metal Fatigue: Effects of Small Defects and Nonmetallic Inclusions. Elsevier Science, Oxford, 305-320.

21. Pul, M., 2017. 7075, 6061 ve 2024 Alüminyum Alaşımlarının Tornalanmasında Yüzey Pürüzlülüğü ve Takım Aşınmasının 
Karşılaştırılması. Uluslararası Mühendislik Araştırma ve Geliştirme Dergisi, 9(2), 65-75.

22. Murakami, Y., Tsutsumi, K., Fujishima, M., 1996. Quantitative Evaluation of Effect of Surface Roughness on Fatigue Strength. Transactions of Japan Society of Mechanical Enginners Ser. A, 62(597), 1124-1131.

23. Boothroyd, G., 1981. Fundamentals of Metal Machining and Machine Tools, International (Fifth Edition), McGraw-Hill, ISBN 0-07-085057- 7, New York.

24. Shaw, M.C., 1984. Metal Cutting Principles, Oxford University Press, London, ISBN 0-19-859002-4, 594. 